\title{
Evaluation of brittle fracturing in the sedimentary rock through laboratory analysis and computer simulation
}

\author{
Matthew TONKINS ${ }^{1 *}$, Alejandro FERNANDEZ GUIJARRO ${ }^{2}$, Alonso GULLON \\ BUCETA ${ }^{3}$, Matthew EYRE ${ }^{4}$, Dariusz, JASIULEK ${ }^{5}$ and John COGGAN ${ }^{6}$
}

\author{
Authors' affiliations and addresses: \\ ${ }^{1}$ Camborne School of Mines, University of Exeter, \\ Penryn, TR10 9EZ, UK \\ e-mail:m.tonkins2@exeter.ac.uk \\ ${ }^{2}$ Geocontrol S.A., Madrid, Cristobal Bordi u u 19-215, \\ Spain \\ e-mail: alonso.gullon@geocontrol.es \\ ${ }^{3}$ Geocontrol S.A., Madrid, Cristobal Bordi u 19-215, \\ Spain \\ e-mail: alonso.gullon@geocontrol.es \\ ${ }^{4}$ Camborne School of Mines, University of Exeter, \\ Penryn, TR10 9EZ, UK \\ e-mail:m.eyre@exeter.ac.uk \\ ${ }^{5}$ KOMAG Institute of Mining Technology ul. \\ Pszczynska 37, 44-101 Gliwice, Poland \\ e-mail: djasiulek@komag.eu \\ ${ }^{6}$ Camborne School of Mines, University of Exeter, \\ Penryn, TR10 9EZ, UK \\ e-mail: j.coggan@exeter.ac.uk \\ *Correspondence: \\ KOMAG Institute of Mining Technology ul. \\ Pszczynska 37, 44-101 Gliwice, Poland \\ tel.: +48 322374443 \\ e-mail:djasiulek@koma.eu \\ Funding information: \\ Research Fund for Coal and Steel (RFCS) \\ Grant Agreement number 752504

\section{Acknowledgement:} \\ The article was prepared based on research \\ conducted within the Research Project: Productivity \\ and Safety of Shield Support (PRASS III)-co- \\ financed by European Commission-Research Fund \\ for Coal and Steel (No. 752504) and Polish Ministry \\ of Science and Higher Education. \\ How to cite this article: \\ Tonkins, M., Fernandez Guijarro, A., Gullon \\ Buceta, A., Eyre, M., Jasiulek, J. and Coggan, J. \\ (2021). Evaluation of brittle fracturing in the \\ sedimentary rock through laboratory analysis and \\ computer simulation. Acta Montanistica Slovaca, \\ Volume 26 (4), 634-648 \\ DOI: \\ https://doi.org/10.46544/AMS.v26i4.04
}

\begin{abstract}
Estimation of the mechanical responses of a sample of rock is a critical characteristic to estimate the responses of rock strata under stress. In this paper, laboratory tests analysis and numerical modelling are used to analyse and replicate intact rock materials. Laboratory and petrographical analyses were undertaken to characterise the brittle response to the uniaxial loading of selected sedimentary samples. Complementary numerical modelling of virtual uniaxial compression tests is carried out using 3DEC software. These models were developed through a Grain Based Model capable of reproducing brittle failure of rocks, for which Voronoi 3D tessellation was generated. Failure mechanisms observed in laboratory and non-linear behaviour due to fracture propagation have been reproduced. Virtual modelling of intact rock with Discrete Element Code would allow, in combination with Discrete Fracture Networks, the numerical analysis of rock mass scale effects and anisotropy through Synthetic Rock Mass (SRM) modelling.
\end{abstract}

Keywords

Brittle Fracture, Voronoi, UCS simulation. 


\section{Introduction}

This research was conducted as part of the RFCS-funded PRASS III project, which focuses on improvements to shield support operation for safety and productivity. One of the objectives of this project is to characterise the brittle response of the super incumbent strata (Blatnicky, M. 2020). The geomechanical response of intact rock to applied loading and subsequent changes in stress is a fundamental characteristic to determine and is essential for the evaluation of safe working conditions within coal mines in terms of strata control. This data is collected through the use of laboratory testing techniques, of which uniaxial compression tests are the most common.

In the most basic form, the uniaxial test provides the Uniaxial Compressive Strength (UCS), which represents the level of stress applied to the sample before failure occurs. The stress-strain relationships of the loaded sample in both the axial and lateral directions provide indications as to deformational characteristics prior to and postfailure. However, while the ultimate strength of the sample provides the maximum stress that the rock can take prior to failure, various critical stresses exist, which, once breached, can have a profound effect on the long-term strength of the rock. These stress states can be determined through the recording of acoustic emissions, which can be matched to the brittle fracturing process defined by Martin and Chandler (1994).

Brittle fracture mechanics is a complex process involving nucleation, growth and coalescence of microcracks. Therefore, the textural, mineralogical and historical tectonic processes the rock has been subjected to can play an important role in the brittle fracture characteristics of the rock sample (Bell, 1978; Howarth and Rowlands, 1987; Hsieh et al., 2008; Singh, 1988; Sun, Wang, and Wang, 2017; Ulusay, Tureli, and Ider, 1994).

There has been a recent increase in the use of numerical simulations of rock to determine the mechanical characteristics to aid in increasing sample counts when there is a deficit in sample numbers due to the potential lack of available samples for test work, either due to poor ground conditions or financial constraints during site investigation (Figiel, A. and Klačková, I. 2020). Virtual testing of rock masses has also been undertaken, coupling laboratory intact rock data and rock mass fractures for improved understanding of rock mass behaviour and calibration of more precise 'continuum' models for large scale applications (Mas Ivars et al., 2011). This paper utilises a synthetic rock mass approach to model the brittle failure process and compares instrumented laboratory test work, together with petrographic observations of fracturing to validate the approach taken.

\section{Literature Review}

\section{The Brittle Fracture Process}

Experimental research shows that the failure process in brittle rocks under compression is characterised by complicated micro-mechanical processes, including the nucleation, growth and coalescence of microcracks, which lead to strain localisation in the form of macroscopic fracturing (Kuric, I. 2021). The evolution of microcracking, typically associated with the emission of acoustic energy, results in a distinctive non-linear stress-strain response, with macroscopic strain-softening commonly observed under low-confinement conditions. Furthermore, unlike other materials (for instance, metals), rocks exhibit a strongly stress-dependent mechanical behaviour. Under laboratory conditions, a variation of failure mode, from axial splitting to shear band formation, is often observed for increasing confining stresses. This variation in failure behaviour is reflected in a non-linear failure envelope and in a transition from brittle to the ductile post-peak response.

Previous research has shown that an instrumented uniaxial compression test can be used to observe and record deformational behaviour and brittle fracture propagation of rock under compressive loading conditions (Eberhardt, 1998; Eberhardt, 1998; Cai et al., 2004; Diederichs, Kaiser, and Eberhardt, 2004; Ghazvinian et al., 2012; Hoek and Martin, 2014). Analysis of the axial, lateral and volumetric strain versus axial stress and acoustic response under compressive loading allows identification of specific deformation phases and damage thresholds, including crack closure (CC), linear elastic deformation, crack initiation $(\mathrm{CI})$, stable crack propagation and subsequent coalescence and crack damage (CD) leading to ultimate failure. Guidance for the identification of the appropriate thresholds from laboratory data is provided in Eberhardt (1998), Diederichs, Kaiser, and Eberhardt (2004), Ghazvinian et al. (2012), and Martin and Chandler (1994). Figure 1 shows the stages of crack propagation suggested by Martin and Chandler (1994) that has been adopted for this research for the identification of critical stress magnitudes under unconfined uniaxial compression.

The role of textural characteristics on brittle fracturing have been previously studied on a range of different rock types and can be grouped into textural and mineralogical characteristics. The textural characteristics relate to the shape, size, arrangement and density of the component grains (Kuric, I., Tlach, V. 2021). From the literature, the effect of grain size appears the most common and varies in accordance with the type of rock studied (Hsieh et al., 2008). For granular rocks, such as sandstones, there is typically an inverse relationship between the average grain size and the uniaxial compressive strength (Martin and Chandler, 1994; Singh, 1988; Ulusay, Tureli, and Ider, 1994). However, it has been claimed that the relationship only holds if the sandstone is homogenous and can be affected by the presence of pores (Palchik, 1999). Kranz (1979) investigated the role of pore spaces on the 
brittle fracturing of sandstones and found that upon loading, the pore spaces act as stress concentrators and alter the stress distributions leading to differences in mechanical responses (Pástor, M., 2020).

The effect of grain shape has not been addressed to the same degree as the grain size in previous research, with most authors noting that there is no evidence of a strong correlation to the uniaxial strength (Ulusay, Tureli, and Ider, 1994). However, the shape of the grain can aid in the packing of the grains, which has shown some good correlations to the UCS. Onodera and Kumara (1980) noted that mineral grains increased in circularity as the rock is brought towards the UCS, signifying breakage along the grain boundaries under compression. This change in grain shape can decrease the degree of grain interlocking, potentially reducing the ultimate strength.

The mineralogical characteristics are linked to the textural characteristics. However, it has been found that texture was more important than mineralogical characteristics when relating to the engineering characteristics (Bell, 1978; Tugrul and Zarif, 1999). It has been shown that the percentage of quartz leads to an increase in rock strength. Yusof and Zabidi (2016) showed that the ratio of quartz and feldspar was inversely proportional to the UCS value. This was attributed to the higher degrees of alteration and intra-granular fracturing associated with the weaker feldspars (Sun, Wang, and Wang, 2017) and/or from the structural interlocking of the quartz grains (Howarth and Rowlands, 1987).

\section{Numerical Simulations of UCS tests}

During recent years, the development of numerical modelling codes has significantly improved the modelling of rock behaviour (Saga, M. 2020). Numerical replication of brittle rock behaviour provides a better understanding of phenomena such as crack initiation and propagation, the influence of microheterogeneity under compression (Lan, Martin, and Hu, 2010), or jointed rock-like material behaviour (Cao et al., 2018). Moreover, rock mass scale effects and anisotropy have been addressed by the Synthetic Rock Mass (SRM) modelling (Mas Ivars et al., 20101; Mas Ivars, 2010; Sentyakov et al., 2020), where intact rock is combined with Discrete Fracture Networks (DFN), allowing virtual testing at the rock mass scale. A stress-strain diagram showing the stages of crack development is presented in figure 1.

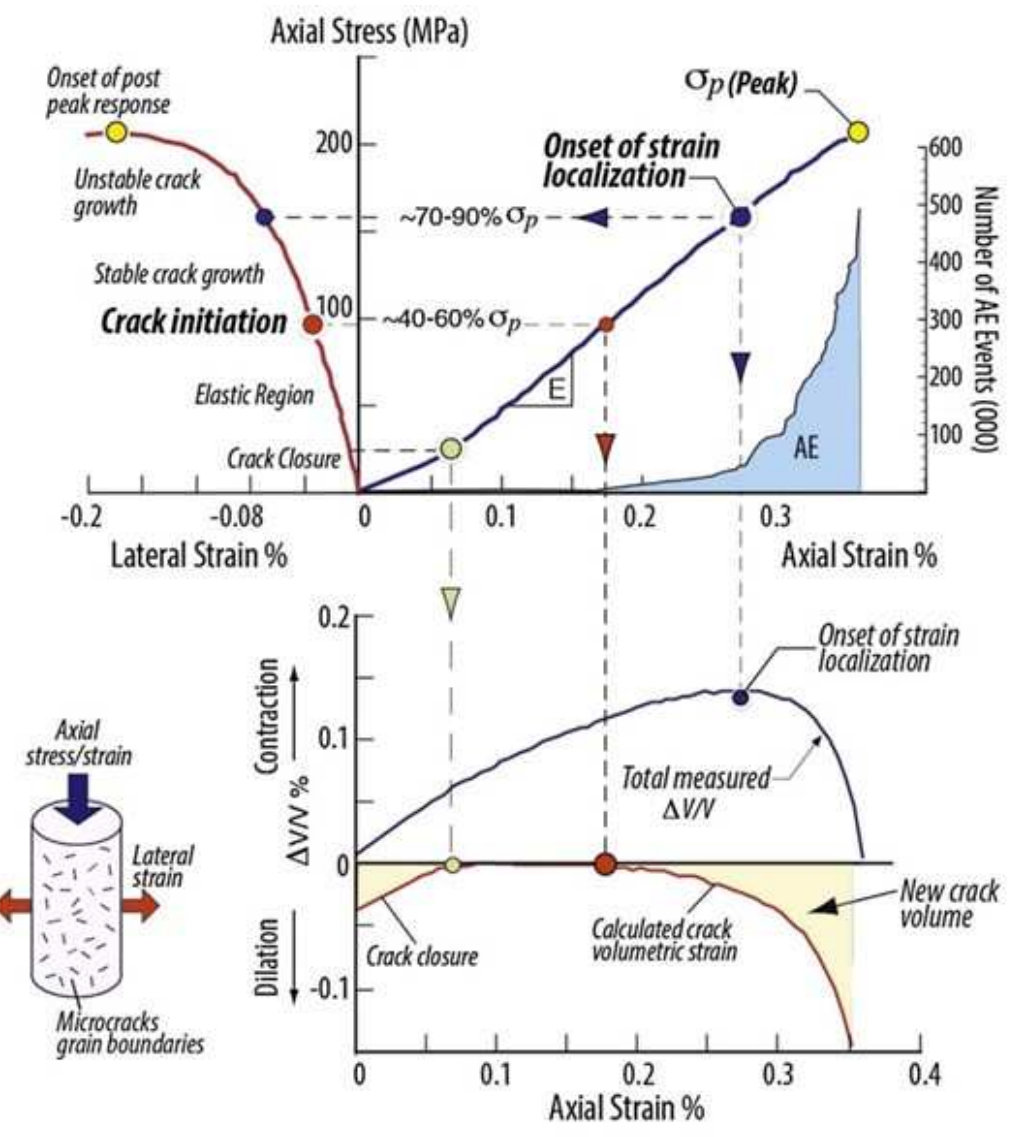

Fig. 1. Stress-strain diagram showing the stages of crack development (Hoek and Martin, 2014; Mas Ivars, 2010) to include joints, or particle clumping (Bahrani, Kaiser, and Corkum, 2018), to avoid the lack of particle interlocking of conventional BPMs

Virtual rock testing can be undertaken using continuum models, although the underlying assumptions need to incorporate the detrimental effects of a discontinuous rock mass. One of the main alternatives used for numerical modelling of brittle rock is the Bonded Particle Model (BPM) developed by Potyondy and Cundall (2004). In this 
model, the rock material is replicated through the assembly of a series of circular (2D) or spherical (3D) particles, bonded together with both perpendicular and parallel bonds, where interaction between particles is developed. These models have been widely implemented within PFC (particle flow code) software (Cao et al., 2018; Vallejos et al., 2014; Vallejos et al., 2013). Recent additions to the original BPM have been developed, such as the SmoothJoint Contact Model (SJCM), developed by Discrete Element Method (DEM) is also widely used for modelling of rock, where the rock structure is represented as an assembly of blocks. These blocks or grains may be either rigid or deformable, and they can represent the real microstructure of the rock or a stochastic distribution of flaws or fracture network, allowing internal fracture development and physical separation between grains. The discretisation of the rock matrix in blocks is commonly carried out in 2D using Voronoi tessellation (Lan, Martin, and Hu, 2010; Fabjan, Ivars, D.M., and Vukadin, V., 2015) or triangular/tetrahedral blocks (Gao, Stead, and Coggan, 2014; Gao, 2013). A comparison between Voronoi and triangular (trigon) blocks was performed by Mayer and Stead (2017), who observed that the different degree of block interlocking of both models derived in a higher localised tensile failure for Voronoi blocks and a predisposition towards the shear failure of triangular meshes.

Two-dimensional applications of Voronoi tessellation are significantly more frequent due to the embedded Voronoi generator of Universal Discrete Element Code (UDEC, (Itasca Consulting Group, 2014)) and the reduced calculation times compared to 3D modelling. The 3D version of the software (3DEC, (Itasca Consulting Group, 2013)), however, does not allow 3D Voronoi discretisation, which must be developed externally. Ghazvinian, Diederichs, and Quey (2014) show a series of numerical Unconfined Compressive Strength (UCS) carried out with 3DEC software, whose Voronoi 3D tessellation is developed by means of an external library for polycrystals generation called Neper. In this research, a different approach for grain mesh generation has been developed, which is described in the next section.

\section{Virtual Testing methodology}

In this research, the first analyses were carried out in 2D using UDEC software (Itasca Consulting Group, 2014), alongside the literature review of previous work. These preliminary analyses were intended to provide some insights into the behaviour of Voronoi tessellation models and the qualitative relations between micro-parameters and macro-scale results. Different approaches were tested in terms of numerical implementation of loading mechanism, monitoring measurements (Cernecky et al., 2015), constitutive models or grain/sample geometries, and a brief sensitivity analysis was carried out.

After the 2D initial stage, the focus was given to 3D modelling in order to be able to include three-dimensional DFN data in a later stage of the process. The first step for the numerical modelling of rock samples was the generation of the three-dimensional Voronoi block mesh. The lack of 3DEC software of an internal generator required the use of external software. For this case, it was decided to use Rhinoceros (Robert McNeel \& Associates, 2015), a 3D computer-aided design (CAD) application software based on NURBS surfaces. More specifically, Voronoi geometry was generated with Grasshopper visual programming language, embedded within Rhinoceros, and afterwards exported to 3DEC using C\#/Python scripts.

The initial mesh was generated from a prism containing 3000 grains. This geometry was later cut to a cylindrical shape after exporting to 3DEC, leaving a sample of laboratory dimensions as shown in Figure 2. For this study, Voronoi tessellation was used to allow physical fragmentation of the rock matrix and random distribution of potential fracture paths, being not intended to reproduce the real microstructure of grains. This way, the number of grains was kept low to allow the analysis of high dimension samples, including DFN for scale effect in a later stage of the project, while keeping the average size of grains constant. As a reference starting point, it was intended to generate at least 10 grains within the sample diameter.

Once the Voronoi tessellation was obtained, the geometry was completed through the generation of prismatic blocks representing the loading plates. In order to reduce calculation times, grains were modelled using rigid blocks, which interact through inter-grain contacts. These contacts were defined with the 3DEC joint constitutive model "joint area contact", which reproduces an elastic joint with a Mohr-Coulomb yield criterion. The sample loading process was simulated, setting a constant velocity at the loading plates and a stress boundary condition to represent confinement at the sample surface when triaxial loading was intended. In order to further save calculation times while keeping a static response, loading tests were carried out according to a velocity's variation process. First attempts to optimise calculation times were carried out under servo-controlled algorithms based on a previously developed tool with UDEC in 2D models, which automatically adjusted velocities according to unbalanced forces and ratios. However, these algorithms were found not to be applicable in $3 \mathrm{D}$ calculations, so a different approach was developed.

Final models were developed following an iterative calculation where loading velocities were automatically adjusted by strain intervals, with the highest velocities for the initial elastic period and the lowest velocities around the pre-peak and post-peak section. Loading velocities were linearly variated between constant velocity intervals and at the initiation of the test, avoiding excessive inertial effects in boundary conditions that could affect the results. To determine the strain thresholds around which velocity changes must be developed for each test, a first fast preliminary run is carried out to estimate the strain values leading to fracture triggering and peak strength. For 
some samples, an additional preliminary calculation with higher velocities can be required to better adjust strain thresholds. This iterative process proved to be more efficient for the analysed cases than the initial servo-control, whose parameters (e.g. force ratio limits) had to be adjusted to the number of grains.

A

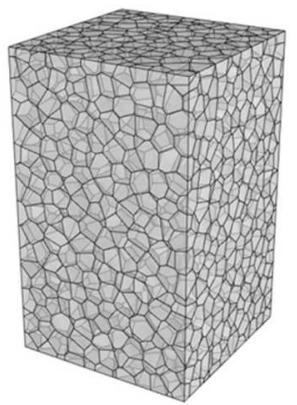

B

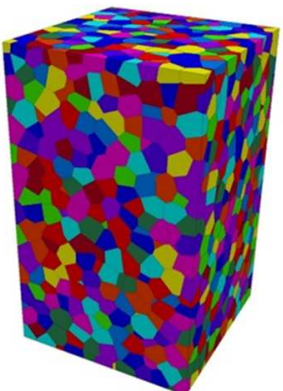

C

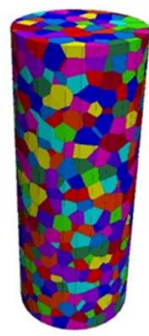

Fig. 2. Voronoi 3D block generated in Rhinoceros (A). The same block once imported to $3 D E C$ (B) and cylindrical sample after cutting (C)

Axial stress measurement was carried out at the loading plates, averaging the forces induced by boundary grains, divided by the cross-sectional area of the sample. The axial strain was directly measured from loading plates displacements, and the lateral strain was estimated from the relative radial displacements of 12 points distributed in three cross-sectional planes at $40 \%, 50 \%$ and $60 \%$ of the sample height. Within each plane, two points measured strain in "x" direction and the other two in " $y$ " direction, with a margin to the sample border of 0.05 times the diameter. The volumetric strain was afterwards calculated from axial and lateral strains. Fracturing was monitored by controlling the number of new broken contacts per strain increment and the total number of fracture evolution.

Regarding material calibration (joints), seven input properties for the joint constitutive model were considered, of which two of them were assumed constant: the residual value of the friction angle " $\varphi r$ ", remaining equal to the initial value, and the residual value of the cohesion " $c r$ ", considered equal to zero. As a reference, sensitivity analyses of Voronoi input parameters carried out in a previous stage of the project in $2 \mathrm{D}$ were taken into account, as well as results shown by Ghazvinian, Diederichs, and Quey (2014) for 3D modelling of Voronoi samples and 2D sensitivity analysis carried out by Fabjan, Ivars, D.M., and Vukadin, V. (2015). Although these authors used elastic instead of rigid grains, some qualitative relations between microparameters and test results have been found to remain of use.

In a simplified manner, the calibration process starts with the elastic modulus $(E)$, strongly influenced by the normal stiffness of discontinuities or joints $(K n)$. In comparison with elastic-grain models, the value of $K n$ must be much lower in order to account for most of the axial deformability, which is provided by grain modulus in those models. Secondly, the peak strength is approached by combining parameters $c$ and $\varphi$. To account for the lateral deformation of the sample (calibration of the apparent Poisson ratio), two main micro-parameters are adjusted: the contact stiffness ratio $K n / K s$ and the $c / \sigma T$ ratio. The first one directly affects the lateral deformation of the sample and also partially the axial deformation, after which re-adjustments of $K n$ may be needed. The second one $(c / \sigma T$ ratio) significantly influences the tensile crack initiation point, leading to the transition from the initial elastic stage to the progressive degradation of resultant stiffnesses of the test. This ratio proved as well to influence the fracture mechanism and the behaviour of the sample against confinement. Early-stage triaxial tests developed have shown a strong influence of the $c / \sigma T$ ratio on the equivalent Hoek \& Brown "mi" parameter, although this part of the research is still under development. Apart from the mentioned main relations between calibration parameters and model responses, there are other complex inter-relations that would require a sensitivity analysis to be assessed.

\section{Material and Methods}

To provide the laboratory data to compare to the numerical simulation, 10 sandstones samples were provided from a single site investigation hole, drilled vertically into the super incumbent strata from a Polish Coal mine. To determine the deformational and strength characteristics of the samples, instrumented uniaxial compression tests were carried out under the standards set out by the International Society of Rock Mechanics (ISRM 1974). In addition to the typical suite of sensors used to capture the loading and deformational responses of the sample, such as axial and circumferential strain gauges, acoustic sensors were also attached to the sample to capture the acoustic emissions to allow the characterisation of critical stress magnitudes of the rocks.

Under the ISRM guidelines, each compression test should last between 10 to 15 minutes. To achieve this, displacement control is applied to the automated testing configuration. This is set based on the operators' 
experience of previous test work and is largely controlled by the sample dimensions. For the sandstone samples, a displacement rate of $0.05 \mathrm{~mm} / \mathrm{min}$ was used.

For the analysis of the data, the uniaxial compressive strength is determined as the peak stress achieved during the test. The relation of the axial deformation (axial strain) to the applied stress is realised through an elastic modulus (also known as Young's Modulus) calculated over the central portion of the elastic region (Figure 1). Diametrical strain is taken from the circumferential strain gauge and relates to the changes in circumference, as the sample is axially deformed. By convention, axial compression is a positive force, and therefore, circumferential expansion is negative.

In an effort to increase the understanding of the brittle fracturing of the different rock types, petrographical investigations were also undertaken post-failure to note the control of fracturing within the sample and to provide improved lithological classification. With the limited sample numbers, pre-testing sections were not available. Upon completion of the uniaxial testing, the samples were encased in resin as close as possible to their original form and cut into thin sections for transmitted light petrography work and further analysis using the Scanning Electron Microscope (SEM).

With both the axial and diametrical strains, the Poisson's ratio can be calculated as the ratio between lateral and axial strain and provides a relationship between the different strains. The volumetric strain is also calculated from the axial and diametrical strains and relates to the overall change in sample volume during testing.

Table 1: Key results from test work performed on sandstone samples

\begin{tabular}{|c|c|c|c|c|c|c|c|}
\hline Sample & Grain Class & UCS $(M P a)$ & Unit Weight (kN/m3) & $E(G P a)$ & $v$ & Tensile (MPa) & $V p(m / s)$ \\
\hline E1 & Coarse & 69.7 & 24.3 & 18.2 & 0.21 & 7.5 & 3354.0 \\
\hline$E 2$ & Coarse & 81.0 & 24.2 & 18.9 & 0.16 & $\operatorname{NaN}$ & $\mathrm{NaN}$ \\
\hline E3 & Coarse & 70.9 & 23.9 & 17.8 & 0.09 & 6.8 & 3216.0 \\
\hline E4 & Coarse & 72.6 & 24.0 & 17.8 & 0.15 & $N a N$ & 3204.0 \\
\hline E5 & Coarse & 84.4 & 24.3 & 19.7 & 0.22 & $N a N$ & 3396.0 \\
\hline E6 & Coarse & 63.7 & 24.3 & 17.7 & 0.18 & $N a N$ & 3321.0 \\
\hline E7 & Fine & 103.4 & 25.4 & 18.3 & 0.21 & 8.4 & 3607.0 \\
\hline E8 & Fine & 118.2 & 25.3 & 20.4 & 0.23 & 9.2 & 3554.0 \\
\hline E9 & Fine & 119.9 & 25.6 & 21.1 & 0.19 & $N a N$ & 3775.0 \\
\hline E10 & Medium & 96.1 & 25.6 & 20.6 & 0.23 & 7.5 & 3599.0 \\
\hline
\end{tabular}

\section{Laboratory testing results}

Ten uniaxial tests were conducted on the sandstone samples. Table 1 provides a summary of the results obtained from the tests undertaken. Based on the results, there is an apparent increase in strength associated with the grain size class. The coarse-grained sandstones tested had a UCS of between 63 to $85 \mathrm{MPa}$ with an average of $74 \mathrm{MPa}$. In comparison, the finer-grained sandstones tested between 103 and $120 \mathrm{MPa}$, with an average of 113 $\mathrm{MPa}$. The differences between the unit weights are relatively small, with 24.1 and $25.4 \mathrm{kN} / \mathrm{m}^{3}$ for the coarse and fine sandstones, respectively. Petrographically, there is no significant difference in mineralogy, and therefore the relative changes in unit weight can be attributed to the increased pore spaces within the coarser sandstones in comparison to the finer-grained rocks, which in turn contributes to the lower strengths. This effect is also noticeable within the average p-wave velocities of 3.3 and $3.6 \mathrm{~km} / \mathrm{sec}$ for the coarse- and fine-grained rocks, respectively.

For each sample tested, the axial, lateral and volumetric deformation characteristics were analysed and compared to the acoustic emissions to establish potential regions for Crack Initiation (CI) and Crack Damage (CD). Locating the point at which crack damage (CD) occurs was taken from the change in the volumetric strain from expansion to dilation.

Identification of crack initiation proved more difficult. Typically, the place at which crack initiation occurs can be located by an increase in acoustic emission. However, it is difficult to distinguish from the full acoustic emission spectrums of the sandstones due to the 'noisy' nature of the samples. To reduce the effect of noise, a threshold was applied to the acoustic emissions, which are shown in Figure 3. The base threshold of the sensors was set at $40 \mathrm{~dB}$ (figure 3A). Applying the threshold of $50 \mathrm{~dB}$ (Figure 3B) significantly reduces the number of counts, allowing two dense groups to be formed. Further increasing the threshold to $60 \mathrm{~dB}$ (Figure 3C) removes most of the noise from the crack closure phase. Increasing the threshold to $70 \mathrm{~dB}$ only leaves emissions from the crack damage phase of the brittle failure process (Figure 3D).

The locations of critical brittle fracture stages can be further defined by observation of the stiffness responses to the acoustic emissions, as shown in Figure 4 for sample E1. The crack closure phase is easily recognisable from early high emissions and the reduction in the diametrical strains. Once cracks have closed, then the sample will begin to expand under the axial load, increasing the volumetric strain. The rate of change of the axial and diametrical strains change, marking the start of the crack initiation and entering of the elastic phase of deformation 
at approximately $30 \mathrm{MPa}$. Changes in the axial and volumetric strain mark the beginning of the crack damage phase, from which permanent damage occurs. Past this point, the acoustic emissions peak and can be easily separated with amplitudes in excess of 70dB (Figure 3D).

These key stress magnitudes discussed above are plotted in Figure 5 for sample E1. Figure 6 shows the determined crack magnitudes from all of the sandstone samples. Across all the samples, the levels for crack initiation and crack damage are relatively consistent, with crack initiation forming between 30 and $50 \%$ of UCS and the onset of permanent crack damage occurring from $75 \%$ of the UCS.
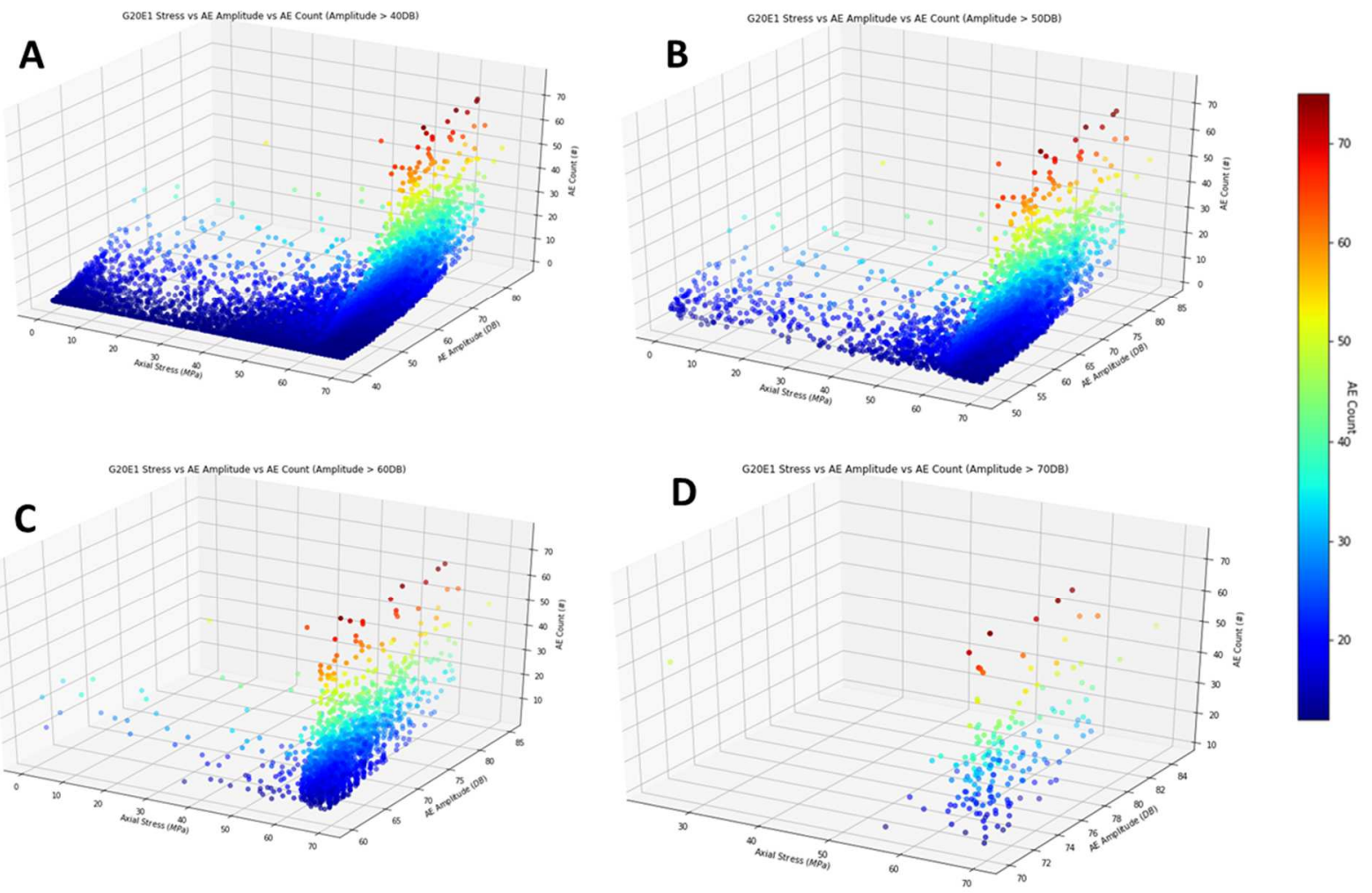

Fig. 3. Acoustic emissions from samples E1 with different minimum levels applied: (A) 40dB, (B)50dB, (C) 60dB, (D) 70dB

\section{Petrographical overview of fracturing}

The sandstone samples are a collection of coarse and fine-grained sandstones that were taken from a single borehole drilled vertically upwards into the super incumbent strata. The sandstone unit appears to contain an upwards fining profile, with coarse-grained sandstones located near the collar, becoming finer with increased depth (fining upwards) within the borehole. Figure 7 shows examples of the different grain sizes from the petrographic section. Sample E1 could be described as a coarse-grained sandstone, whereas sample E7 is fine-grained.

Petrographic analysis of the component grains of the sandstones were predominately quartz $(80-90 \%)$ with between 10 to $20 \%$ muscovite micas, interpreted as an alteration product of plagioclase feldspars. This information can be used to classify the sandstones using the Folk (1980) classification scheme, resulting in a Subarkose Sandstone classification. The quartz grains themselves appear subangular to subrounded. The matrix is predominantly a form of phyllosilicate, potentially sericite and accounts for approximately $5-10 \%$ of the observed samples. A close-up SEM image of the matrix is shown in Figure 8, where the matrix appears to have been squeezed between two quartz grains resulting in flow under uniaxial compression. The platy nature of the matrix is characteristic of a phyllosilicate. 


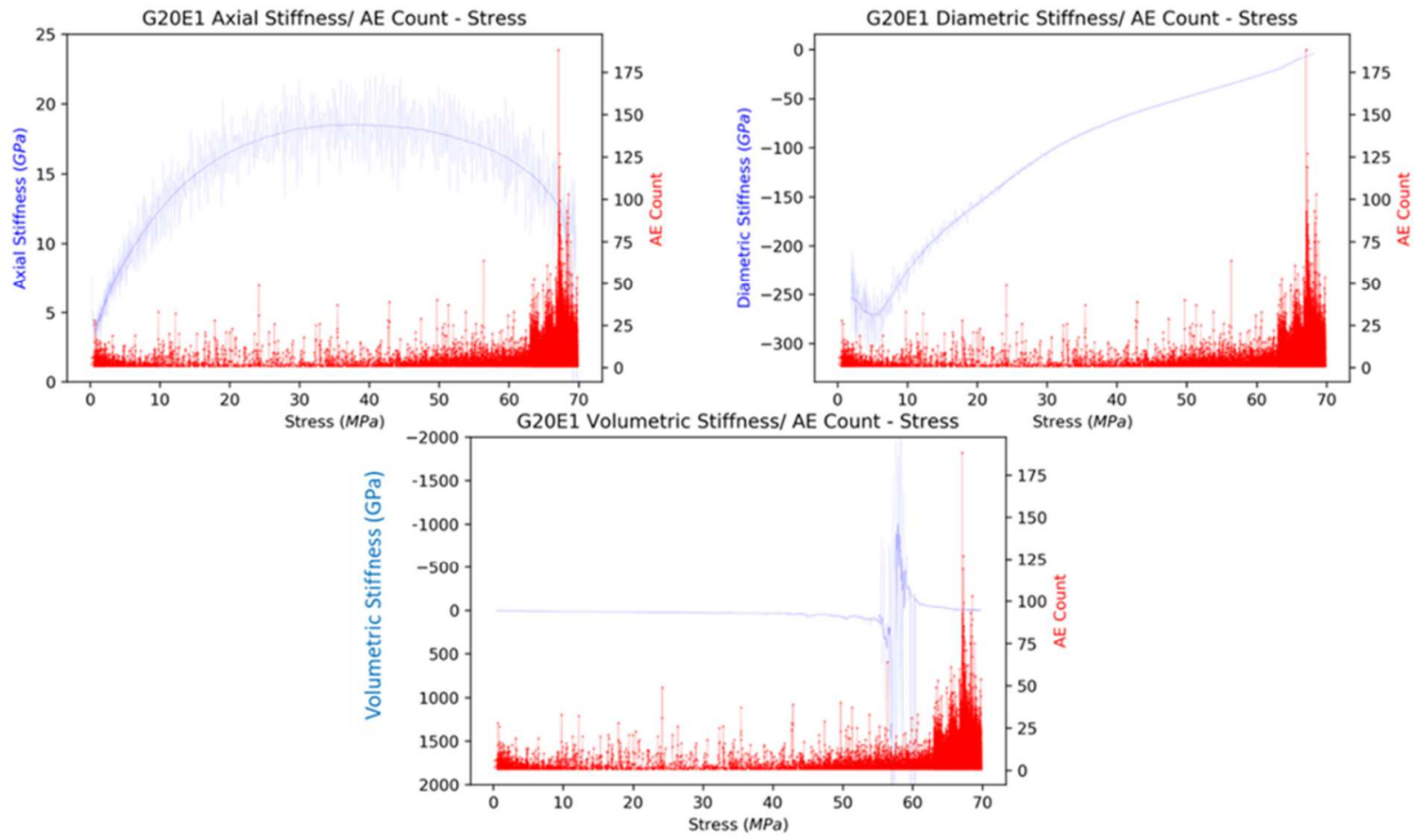

Fig. 4. Stiffness responses compared to the acoustic emissions for sample E1

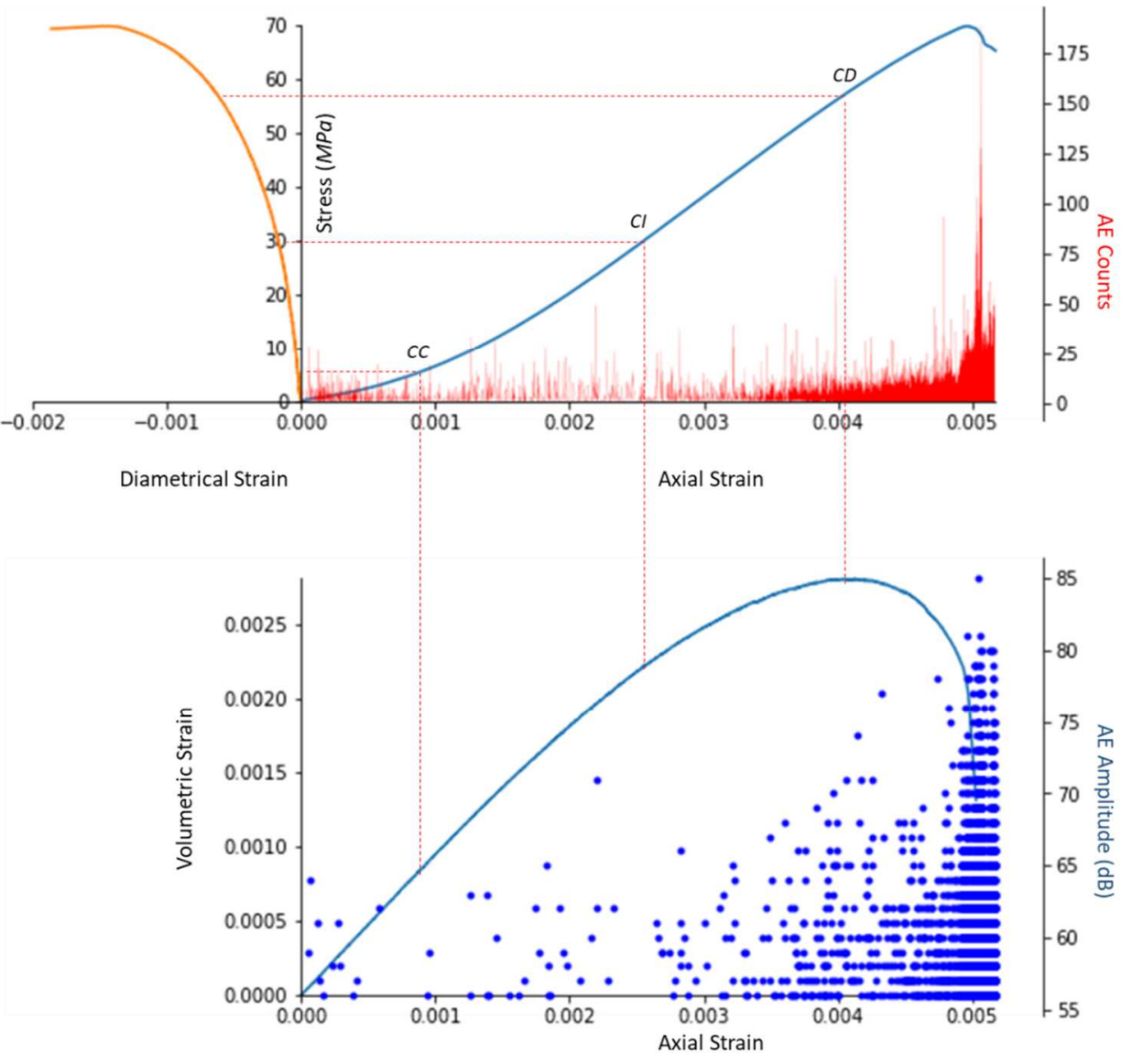

Fig. 5. Brittle failure results from fine-grained sandstone (sample E1)

Smaller variations in texture within some sandstone samples lead to potentially different mechanical characteristics. For example, in sample E2, a band of more porous sandstone with a hard boundary to one end and 
a gradational boundary on the other is shown in Figure 9. The pore spaces appear to hold a form characteristic of a sand grain. It is assumed that these grains were carbonaceous in origin and subsequently removed through dissolution from groundwater. The presence of this band of increased porosity has had a notable effect on the trajectory of the primary fracture under uniaxial compression. It has been noted that the localisation of strain is strongly influenced by the localisation of stresses around pore spaces, as noted as the $4^{\text {th }}$ principle of crack propagation (Kranz, 1979). The process of crack propagation under uniaxial compression is a complex process and largely depends on the lithological characteristics, degree of micro fracturing and conditions of loading. This is evident from the range of primary fractures developed under uniaxial compression, as shown in Figure 10, which shows three different samples of different grain sizes and the associated primary fracture. Sample E2 and E9 show the typical characteristic failure patterns observed under uniaxial compression, with sample E7 showing an approximate hourglass fracture pattern.

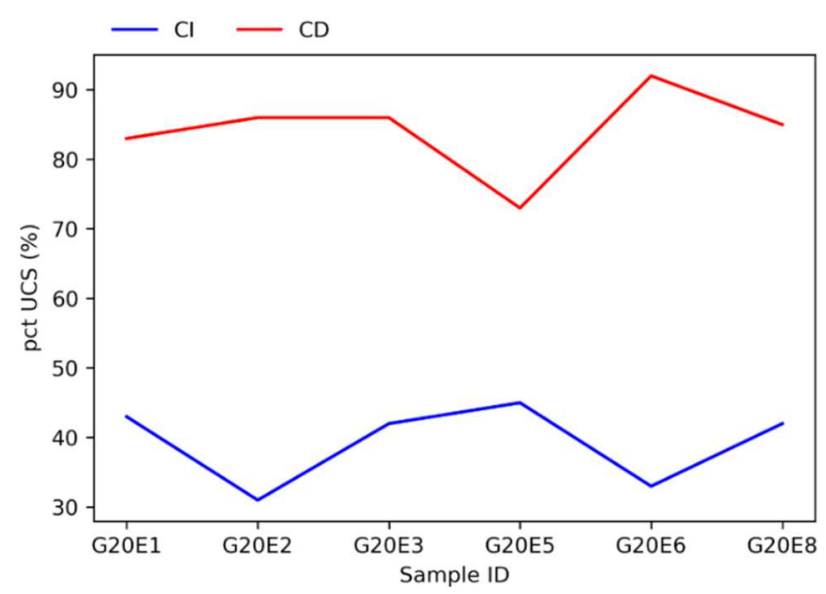

Fig. 6. Stress magnitudes determined from the sandstone samples
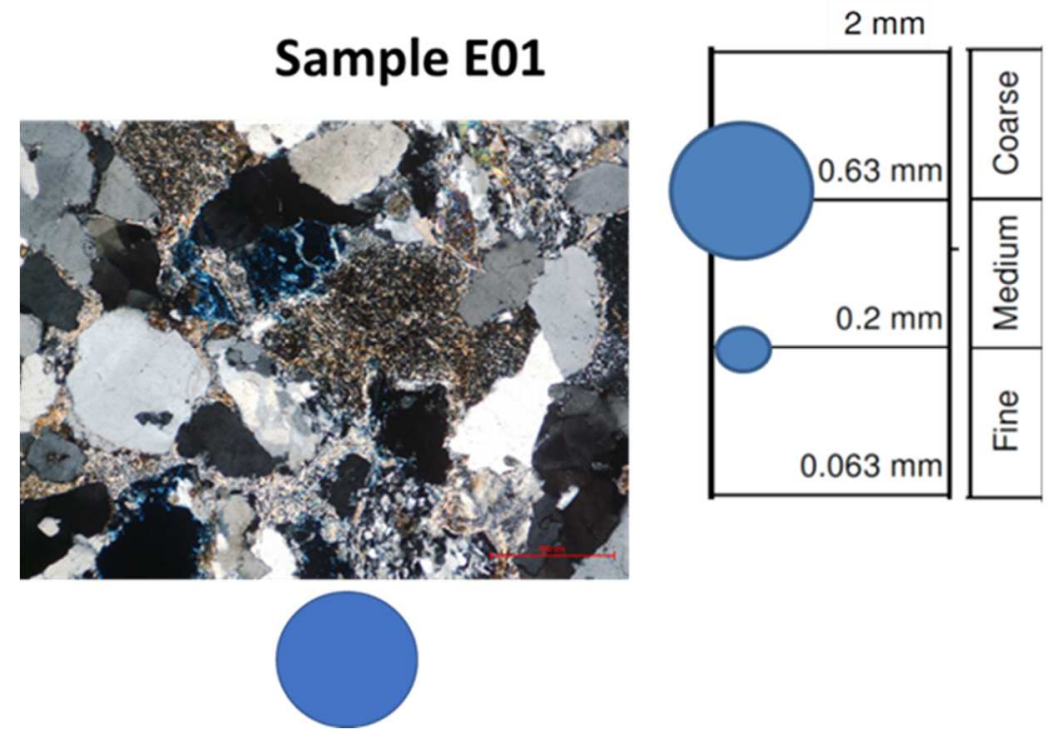

Fig. 7. Grain size comparison of samples E1 and E8 from petrographical sections. Scale is 500 $\mu m$ 


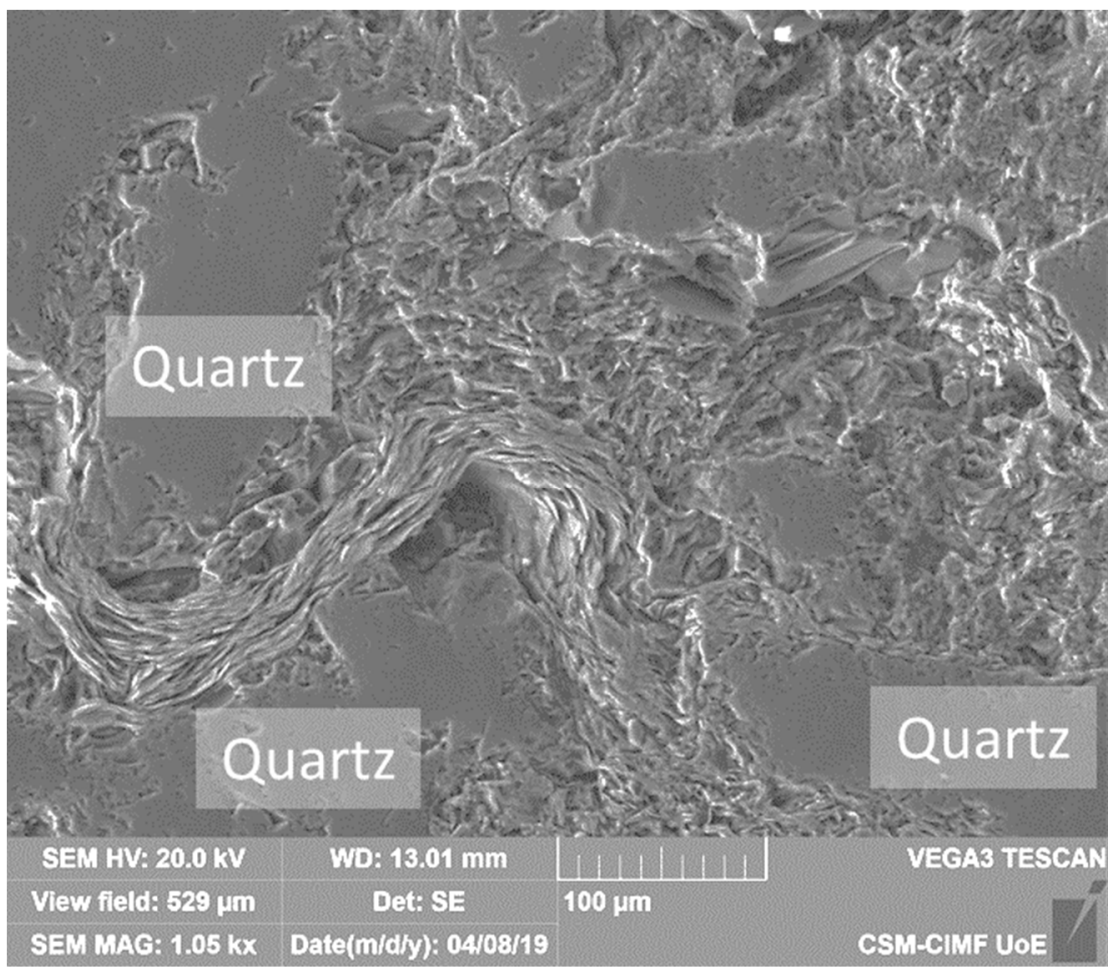

Fig. 8. SEM image of the phyllosilicate matrix of sample E1. The total view is $529 \mu \mathrm{m}$

\section{Numerical Simulation Results}

The behaviour of laboratory tested sandstone is reproduced in Figure 11 utilising the calibrated input microparameters of grain contacts, whose values are shown in Table 2 (shear stiffness is expressed through $\mathrm{kn} / \mathrm{ks}$ ratio). Results obtained for simulated UCS testing are shown in Figure 11, while main macro-response values are presented in Table 3. As can be observed from the figure, the calibrated model correctly reproduces the overall behaviour of sandstone samples previously tested at the laboratory for UCS.

If we assimilate the number of broken contacts of the numerical model to the acoustic emission, it can be observed that numerical modelling results present the CI point at approximately $35 \%$ of the peak resistance. This value is slightly lower than those obtained from laboratory tests, which could be due to the lack of a crack-closure stage and the effect of the mesoscale grain mesh developed for the virtual sample, as well as the predisposition of Voronoi meshes towards localised tensile failure (Mayer and Stead, 2017). Further work could focus on a potential better adjustment of the Voronoi mesh size while keeping a number of elements reasonable for the later high-scale analysis, including DFN.

Table 2: Input parameters used for the calibration fo the Voronoi 3D numerical model in 3DEC

\begin{tabular}{|c|c|c|c|c|c|c|c|c|}
\hline Parameter & $\varphi\left({ }^{\boxplus}\right)$ & $\varphi r$ (回) & $c(M P a)$ & $c_{r}(M P a)$ & $k_{n}(G P a M)$ & & $k n / k s$ & $p h i_{\tau}(M p a)$ \\
\hline Value & 20 & 20 & 45 & & 0 & 35 & 2.3 & 11 \\
\hline
\end{tabular}

Table 3: Macro-response values obtained from virtual modelling

\begin{tabular}{|c|c|c|c|c|c|c|}
\hline Parameter & UCS (MPa) & $E(G P a)$ & $\eta_{a x}(\%)$ & $v$ & $\eta v o l$ & $\mathrm{Cl}(\%)$ \\
\hline Value & 88 & 17 & 5.9 & 0.25 & 0.26 & 35 \\
\hline
\end{tabular}

The modelled failure mechanism is shown in Figure 12. As it can be observed, the main slip plane is generated inside the sample and extended to one of the sides prior to peak strength. This behaviour is in concordance with laboratory test results.

In addition, preliminary numerical triaxial tests were carried out with $3 \mathrm{MPa}$ and $10 \mathrm{MPa}$ confinement, using the same micro-properties as the model calibrated to UCS laboratory data. Adjusting the results from these models to the Hoek \& Brown failure criterion, a value of the "mi" parameter of around 8-9 was obtained. 


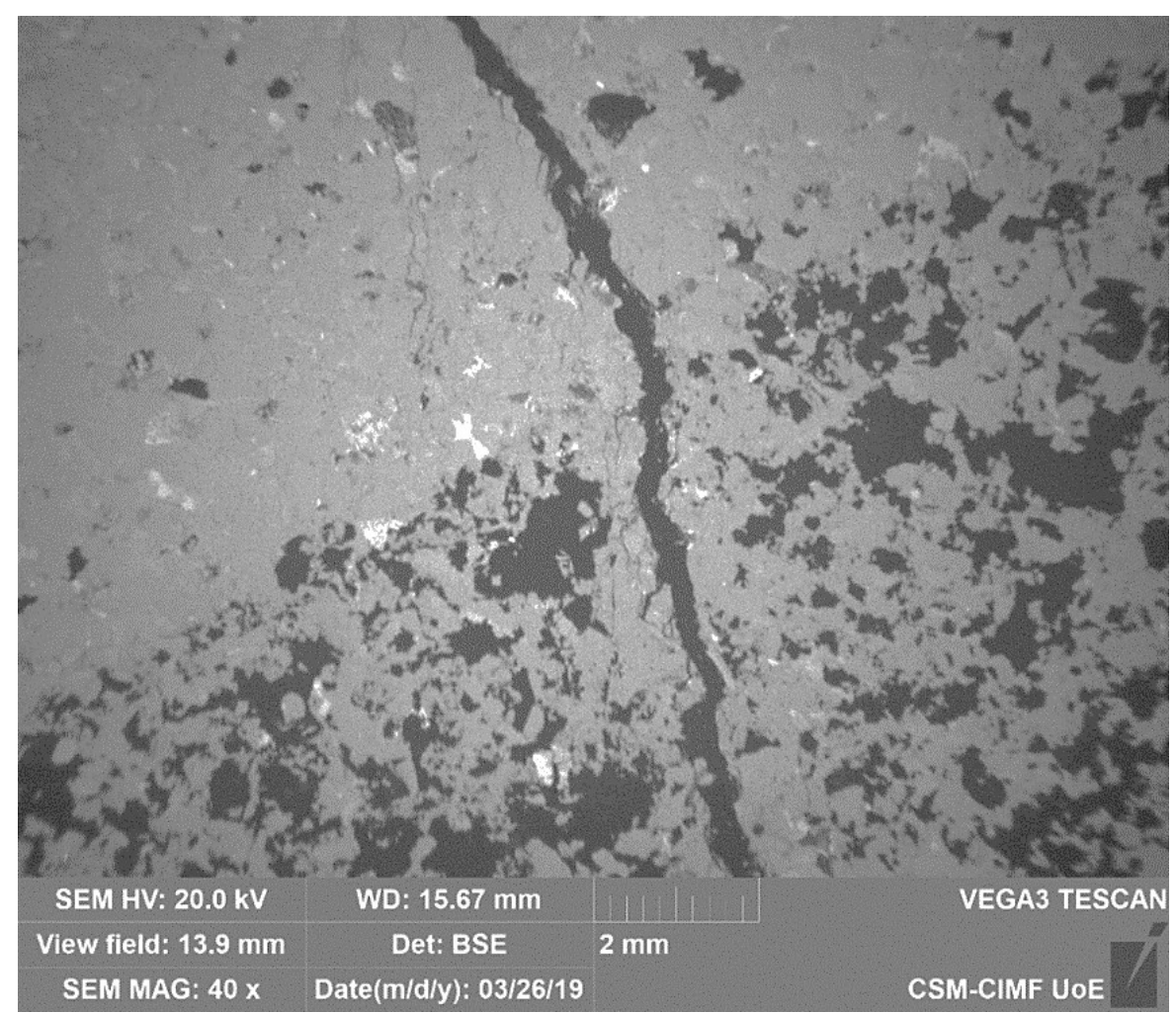

Figure 9: SEM image of sample E2, showing the abrupt transition from Quartz/muscovite to one of the numerous voids. Note how the direction of the fracture alters from the intersection with the voids

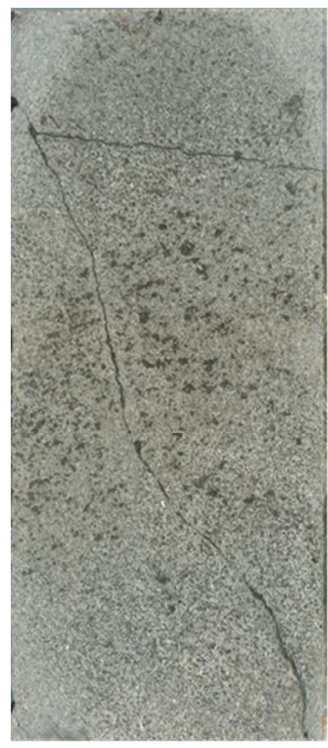

E2

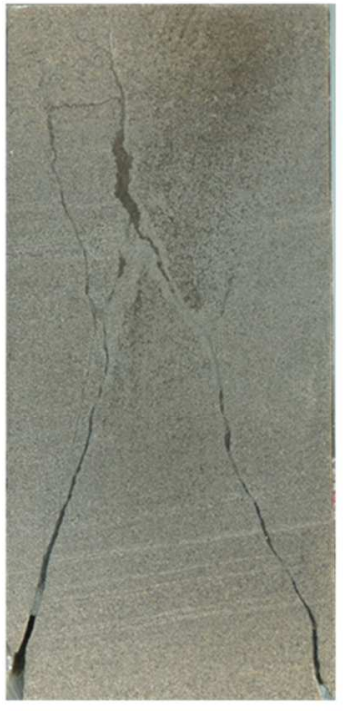

E7

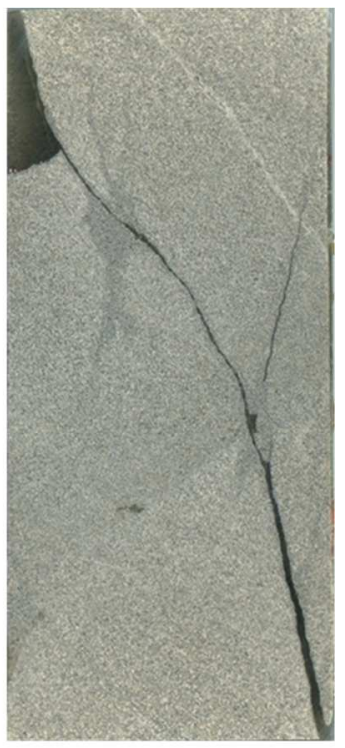

E9

Figure 10: Fracture paths from three sandstone samples 

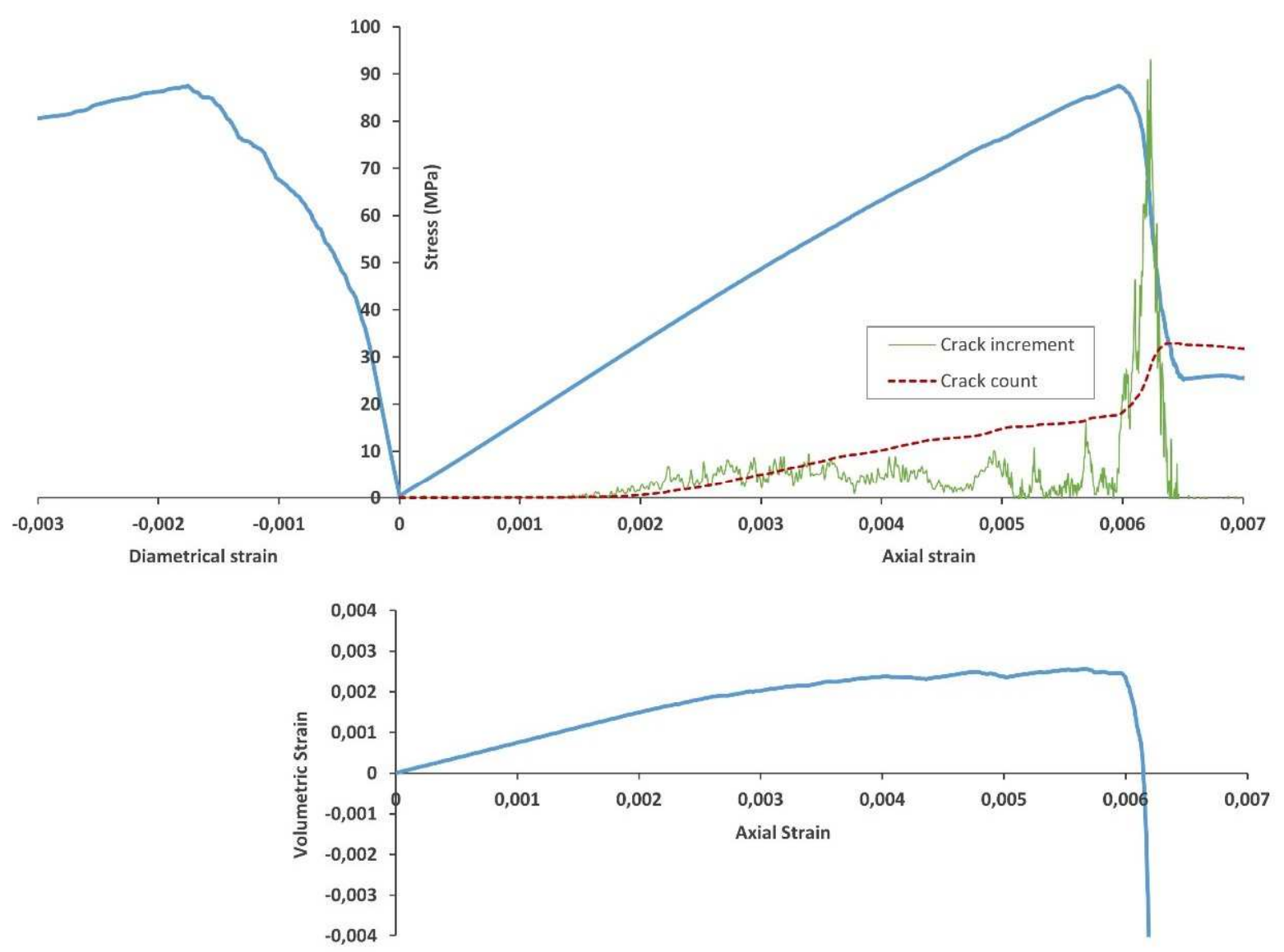

Figure 11: Brittle failure results from the calibrated virtual model of sandstone

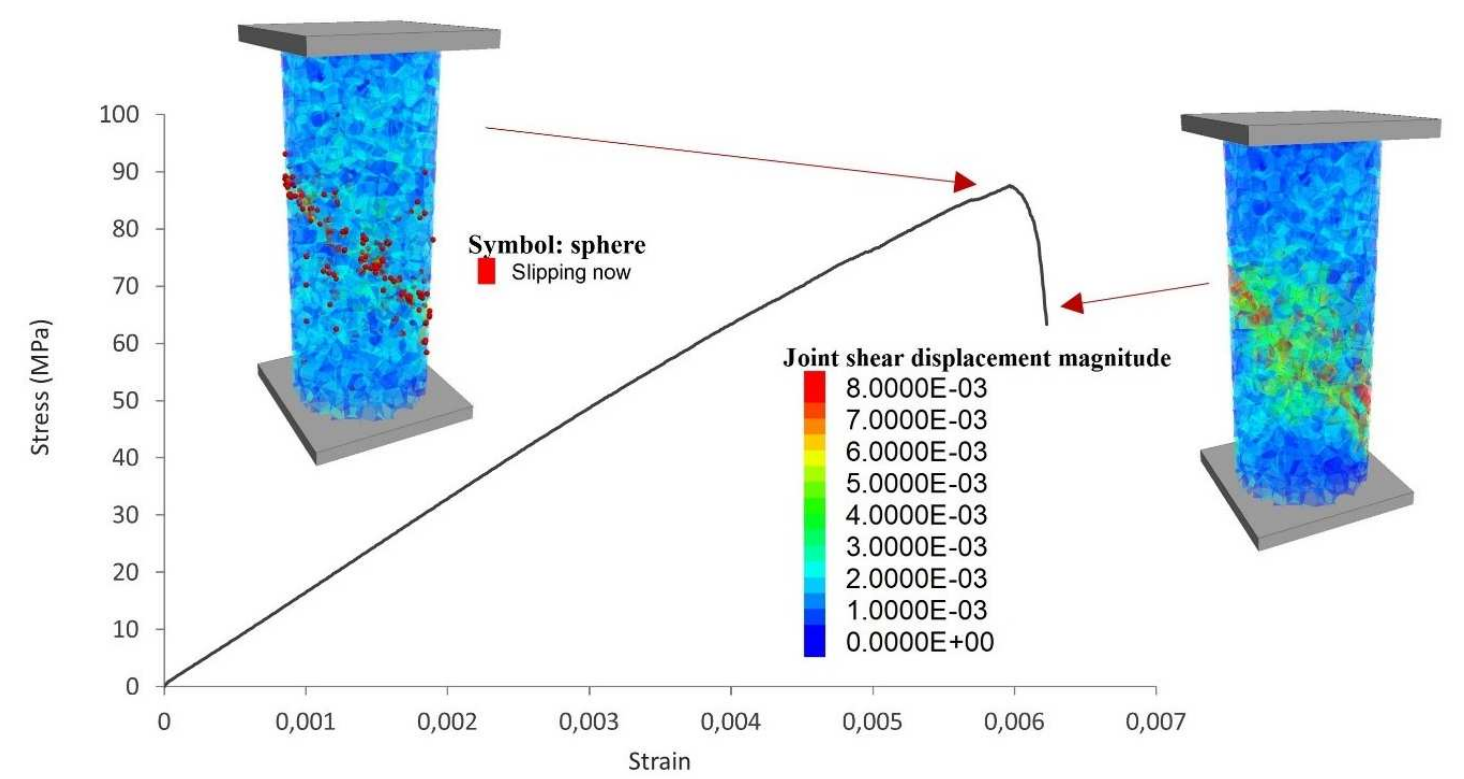

Figure 12: Failure mechanism reproduced by virtual modelling of sandstone, using Voronoi $3 D$

\section{Discussion - Comparison of Laboratory to Simulation}

The results from the laboratory testing and the numerical simulation is shown in Figure 13. For clarity samples E1, E5 for the course, sample E6 and E7 for the fine and sample E10 for the medium sandstones are plotted and compared against the simulated sandstone. 


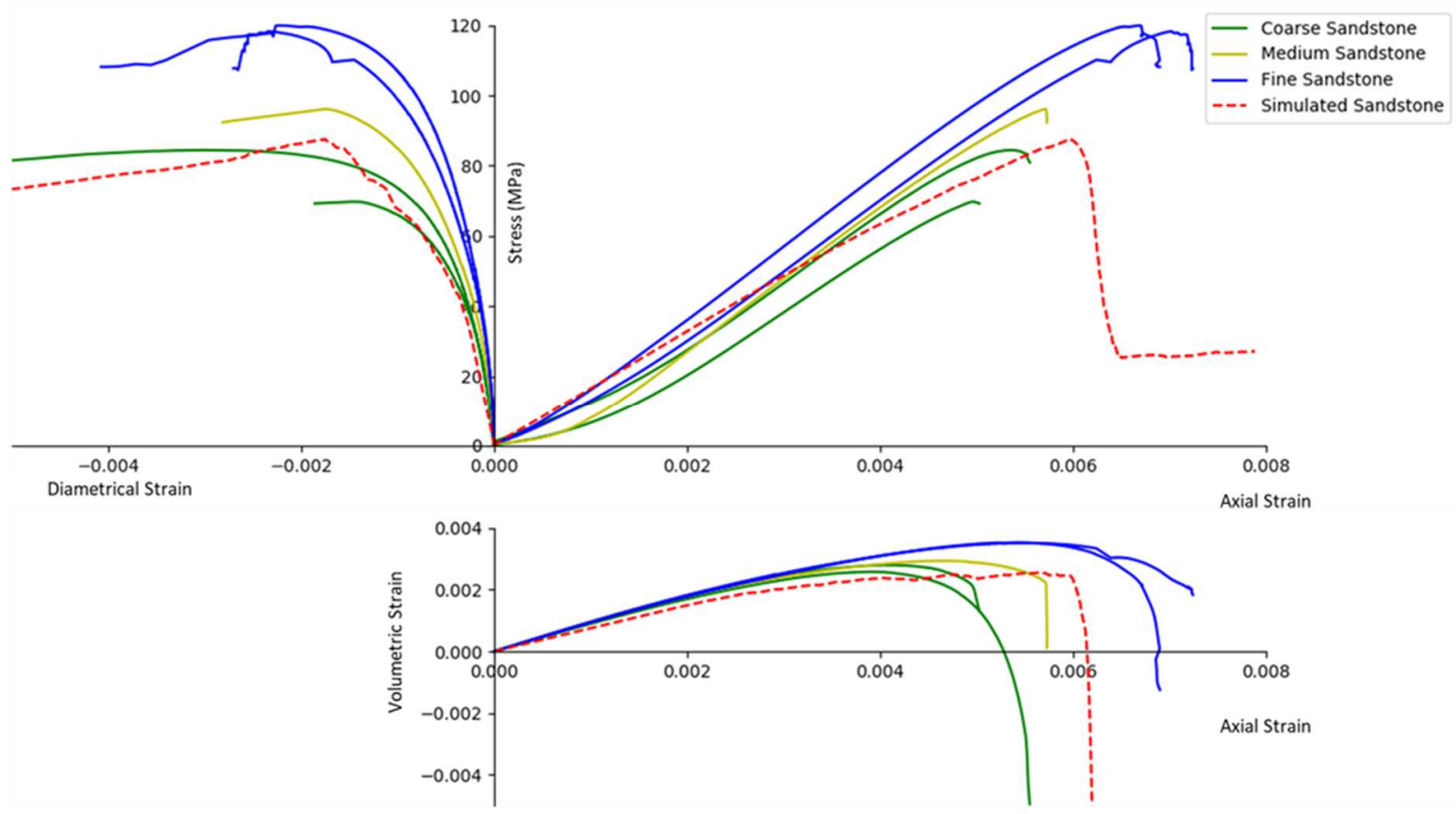

Figure 13: Comparison of the Simulated vs Laboratory tests

The numerical simulation was created as a coarse/medium grained sandstone. The results compare well, producing a UCS value of $88 \mathrm{MPa}$, which plots between samples E5 and E10 and therefore, in terms of grain size to peak strength, the model is a good predictor. Slight differences between laboratory and numerical stress-strain curves arise from the initial increase of the Young modulus shown by laboratory samples due to crack closure, which are not captured by the numerical model in which there is a continuous degradation of $\mathrm{E}$ after crack initiation. The young's modulus of the simulated sandstone is $17 \mathrm{GPa}$, which is approximately $1 \mathrm{GPa}$ lower than the coarse samples. However, this result is still within the range of stiffnesses recorded from coal strata sandstones.

Regarding material behaviour under confinement, a preliminary comparison between laboratory and virtual results was carried out, using the relation between the compressive to tensile strength and the Hoek-Brown parameter "mi" proposed by Hoek and Brown (Hoek and Brown 2019):

$$
\frac{\sigma_{c i}}{\left|\sigma_{t}\right|}=0.81 m_{i}+7
$$

This equation, applied to the values of the "medium" grain class shown in Table 1, leads to a "mi" estimation of 7, slightly lower than the value obtained from numerical triaxial tests, but shows promise and requires some further work.

\section{Conclusion}

The work within this paper focuses on the uniaxial laboratory testing of sandstone samples with different grain sizes. Each sample was prepared and tested under the ISRM guidelines of a uniaxial test (ISRM 1974). Axial and diametrical deformation was recorded and compared to acoustic emissions from the samples under axial load. The results were used to define critical stress magnitudes for each sample in terms of the Crack Closure (CC), Crack Initiation (CI) and Crack Damage (CD) as defined by Martin and Chandler (1994). These magnitudes are used to define the brittle fracturing characteristics of the intact rock and are important to define to understand long term responses to an applied load.

The results from the laboratory tests found that there was a clear inverse correlation between the grain size and the uniaxial compressive strength (UCS), with the finer-grained samples resulting in higher UCS values in excess of $120 \mathrm{MPa}$, dropping with an increase in grain size to a low of $64 \mathrm{MPa}$. The results from the critical magnitudes are relatively similar, with crack initiation starting between 30 to $50 \%$ of the UCS and the onset of permanent crack damage from $75 \%$ UCS. 
The GBM numerical model developed using 3D Voronoi tessellation and rigid grains proved to be capable of reproducing the non-linear behaviour of sandstones for UCS laboratory results, using a low-density mesh of around 10 grains per diameter. The model compared well with the laboratory tests of similar-sized sandstones in terms of UCS and E. While more work is required to simulate a range of different grain sizes and pore spaces, it has been shown to provide good estimates of the intact rock behaviour under low confining pressures.

Further work is going to be carried out from this research. For the laboratory tests, more work is required to test a wide range of textural and mineralogical characteristics to better understand the relationship between textural characteristics, brittle fracturing, and critical stress magnitudes. This work goes in hand with further work on the numerical simulations in terms of unconfined brittle failure by the simulation of different grain sizes and finding the simulation limits in terms of computational requirements. Regarding material behaviour under confinement, further work will focus on analysing the grain size influence on triaxial results, as well as the influence of model micro-parameters on numerical triaxial tests for a better calibration of the virtual model.

\section{References}

Bahrani, N, PK Kaiser, and A Corkum (2018). "Suggested Methods for Estimation of Confined Strength of Heterogeneous (Defected) Rocks". In: Caving 2018. Caving 2018. Perth, Western Australia: Australian Centre for Geomechanics, p. 16.

Bell, F.G. (1978). "The Physical and Mechanical Properties of the Fell Sandstones, Northumberland, England". In: Engineering Geology 12, pp. 1-29.

Blatnicky M., Dizo J., Saga M., Gerlici J., Kuba E. (2020). Design of a Mechanical Part of an Automated Platform for Oblique Manipulation, Applied Sciences-Basel, Vol.10, Issue 23, Article No: 8467, DOI: 10.3390/app10238467, 2020

Cai, M et al. (2004). "Generalized Crack Initiation and Crack Damage Stress Thresholds of Brittle Rock Masses near Underground Excavations". In: International Journal of Rock Mechanics and Mining Sciences 41.5, pp. 833-847.

ISSN: 13651609.

Cao, R.H. et al. (2018). "Failure Characteristics of Jointed Rock-like Material Containing Multi-Joints under a CompressiveShear Test: Experimental and Numerical Analyses". In: Archives of Civil and Mechanical Engineering 18.3, pp. 784- 798.

Cernecky, J., Bozek, P., Pivarciova, E. (2015). A new system for measuring the deflection of the beam with the support of digital holographic interferometry. In Journal of Electrical Engineering. Vol. 66, Iss. 1 pp. 5356.

Diederichs, M.S, P.K Kaiser, and E Eberhardt (2004). "Damage Initiation and Propagation in Hard Rock during Tunnelling and the Influence of Near-Face Stress Rotation". In: International Journal of Rock Mechanics and Mining Sciences 41.5, pp. 785-812.

Eberhardt, E. (1998). "Brittle Rock Fracture, Progressive Damage in Uniaxial Compression". PhD. University of Saskatchewan. 335 pp.

Fabjan, T., Ivars, D.M., and Vukadin, V. (2015). Numerical Simulations of Intact Rock Behaviour via the Continuum and Voroni Tessellation Models: A Sensitivity Analysis.

Figiel, A., Klačková, I. (2020). Safety requirements for mining complexes controlled in automatic mode. In Journal Acta Montanistica Slovaca 2020, Volume 25, 3; ISSN 1335-1788, DOI 10.46544/AMS.v25i3.13.

Folk, R.L (1980). Petrology of Sedimentary Rocks. Austin, Texas: Hemphill Publishing Company. 179 pp. ISBN: 0914696-14-9.

Gao, F. (2013). "Simulation of Failure Mechanisms around Underground Coal Mine Openings Using Discrete Element Modelling". PhD. Simon Fraser University.

Gao, Fuqiang, Doug Stead, and John Coggan (2014). "Evaluation of Coal Longwall Caving Characteristics Using an Innovative UDEC Trigon Approach". In: Computers and Geotechnics 55, pp. 448-460.

Ghazvinian, E., M.S. Diederichs, and R. Quey (2014). "3D Random Voronoi Grain-Based Models for Simulation of Brittle Rock Damage and Fabric-Guided Micro-Fracturing". In: Journal of Rock Mechanics and Geotechnical Engineering 6.6, pp. 506-521. ISSN: 16747755.

Ghazvinian, E. et al. (2012). "Formalized Approaches to Defining Damage Thresholds in Brittle Rock: Granite and Limestone." In: 46th US Rock Mechanics/Geomechanics Symposium. Chicago, USA, pp. 966-974.

Hoek, E. and E.T. Brown (2019). "The Hoek-Brown Failure Criterion and GSI - 2018 Edition". In: Journal of Rock Mechanics and Geotechnical Engineering 11.3, pp. 445-463. ISSN: 16747755.

Hoek, E. and C.D. Martin (2014). "Fracture Initiation and Propagation in Intact Rock - A Review". In: Journal of Rock Mechanics and Geotechnical Engineering 6.4, pp. 287-300. ISSN: 16747755.

Howarth, D F and J C Rowlands (1987). "Quantitative Assessment of Rock Texture and Correlation with Drillability and Strength Properties". In: Rock Mechanics and Rock Engineering 20. 00144, pp. 57 -85. 
Hsieh, Yo-Ming et al. (2008). "Interpretations on How the Macroscopic Mechanical Behavior of Sandstone Affected by Microscopic Properties—Revealed by Bonded-Particle Model". In: Engineering Geology 99.12, pp. 1-10.

ISRM (1974). Sugested Methods for Determining the Uniaxial Compressive Strength and Deformability of Rock Materials.

Itasca Consulting Group (2013). 3 Dimenstional Distint Element Code. Version 5. Minneapolis: Itasca: Itasca Consulting Group.

- (2014). Universal Distinct Element Code. Version 6. Minneapolis: Itasca: Itasca Consulting Group.

Kranz, Robert L (1979). "Crack-Crack and Crack-Pore Interactions in Stressed Granite". In: International Journal of Rock Mechanics and Mining Sciences \& Geomechanics Abstracts 16, pp. 37-47.

Kuric, I., Klačková, I., Nikitin, Y.R., Zajačko, I., Císar, M., Tucki, K. (2021). Analysis of diagnostic methods and energy of production systems drives, In Journal; Processes, MDPI, 9, 843, DOI.org/10.3390/pr9050843

Kuric, I., Tlach, V., Sága, M., Císar, M., Zajačko, I. (2021). Industrial robot positioning performance measured on inclined and parallel planes by double ballbar. In Journal: Applied Science-Basel, eISSN: 2076-3417, volume 11, Issue 4, article number: 1777, pp. 1-18, 2021

Lan, Hengxing, C. Derek Martin, and Bo Hu (2010). "Effect of Heterogeneity of Brittle Rock on Micromechanical Extensile Behavior during Compression Loading". In: Journal of Geophysical Research 115.B1, B01202. ISSN: 0148-0227.

Martin, C.D. and N.A. Chandler (1994). "The Progressive Fracture of Lac Du Bonnet Granite". In: Internal Journal of Rock Mechanics and Mining Sciences 31.6, p. 17.

Mas Ivars, Diego (2010). "Bonded Particle Model for Jointed Rock Mass”. PhD. Stockholm: Skolan for arkitektur och“ samhallsbyggnad, Kungliga Tekniska h" ogskolan."

Mas Ivars, Diego et al. (2011). "The Synthetic Rock Mass Approach for Jointed Rock Mass Modelling". In: International Journal of Rock Mechanics and Mining Sciences 48.2, pp. 219-244. ISSN: 13651609.

Mayer, J.M. and D. Stead (Feb. 2017). "Exploration into the Causes of Uncertainty in UDEC Grain Boundary Models". In: Computers and Geotechnics 82, pp. 110-123.

Onodera, T.F. and H.M Kumara (1980). "Relation between Texture and Mechanical Properties of Crystalline Rocks". In: Bulletin of the International Association of Engineering Geolgists 22.

Palchik, V (1999). "Influence of Porosity and Elastic Modulus on Uniaxial Strength in Soft Brittle Porous Sandstones". In: Rock Mechanics and Rock Engineering 32.4, pp. 303-309.

Pástor, M., Živčák, J., Púškár, M., Lengvarský, P., Klačková, I. (2020). Application of Advanced Measuring Methods for Identification of Stresses and Deformations of Automotive Structures. In Journal; Applied Sciences - Basel 2020, Volume 10, Issue 21, article number 7510, MDPI, ISSN 2076-3417.

Potyondy, D.O. and P.A. Cundall (2004). "A Bonded-Particle Model for Rock". In: International Journal of Rock Mechanics and Mining Sciences 41.8, pp. 1329-1364.

Robert McNeel \& Associates (2015). Rhinoceros Users' Manual. Version 5. URL: www.rhino3d.com.

Saga M., Blatnicky M., Vasko M., Dizo J., Kopas P., Gerlici J. (2020). Experimental Determination of the MansonCoffin Curves for an Original Unconventional Vehicle Frame, Materials, Vol.13, Issue 20, Article No: 4675, DOI: 10.3390/ma13204675, 2020

Sentyakov, K., Peterka, J., Smirnov, V., Bozek, P. and Sviatskii, V. (2020). Modeling of Boring Mandrel Working Process with Vibration Damper. In Materials. Vol. 13, iss. 8 (2020), pp.1-13. DOI: 10.3390/ma13081931

Singh, S. K. (1988). "Relationship among Fatigue Strength, Mean Grain Size and Compressive Strength of a Rock". In: Rock Mechanics and Rock Engineering 21.4, pp. 271-276.

Sun, Wenjuan, Linbing Wang, and Yaqiong Wang (2017). "Mechanical Properties of Rock Materials with Related to Mineralogical Characteristics and Grain Size through Experimental Investigation: A Comprehensive Review". In: Frontiers of Structural and Civil Engineering 11.3, pp. 322-328.

Tugrul, A and I.H Zarif (1999). "Correlation of Mineralogical and Textural Characteristics with Engineering Properties of Selected Granitic Rocks from Turkey". In: Engineering Geology 51.4, pp. 303-317.

Ulusay, R., K. Tureli, and M.H. Ider (1994). Preduction of Engineering Properties of Selected Litharenite Sandstone from Its Petrographic Characteristics Using Correlaton and Multivariate Statistical Techniques.

Vallejos, J A et al. (2013). "Application of the Synthetic Rock Mass Approach to Characterize Rock Mass Behavior at the El Teniente Mine, Chile". In: p. 15.

Vallejos, J.A. et al. (2014). "Characterization and Synthetic Simulation to Determine Rock Mass Behaviour at the El Teniente Mine, Chile. Part II." In: Proceedings of the 3rd International Symposium on Block and Sublevel Caving. 3rd International Symposium on Block and Sublevel Caving. Santiago, Chile.

Yusof, N.Q.A.M. and H. Zabidi (2016). "Correlation of Mineralogical and Textural Characteristics with Engineering Properties of Granitic Rock from Hulu Langat, Selangor". In: Procedia Chemistry 19, pp. 975980. 